\title{
PENGARUH SELF REGULATED LEARNING DAN SELF EFFICACY TERHADAP PRESTASI AKADEMIK MAHASISWA
}

\author{
Yowelna Tarumasely \\ IAKN Ambon \\ email: yowelnatarumasely@gmail.com
}

\begin{abstract}
This study aims to determine: the effect of self-regulated learning on student academic achievement, (2) the effect of Self Efficacy on academic achievement; (3) the influence of Self Regulated Learning and Self Efficacy on Academic achievement. The population in this study were 70 students in Semester II, the research sample as much as the population, namely 70 students. The method used is multiple linear regression analysis. The results showed that: (1) Self regulated learning had no effect on student academic achievement, (2). Self-efficacy has a significant effect on student academic achievement, and (3) Self regulated learning and Selfefficacy simultaneously affect student academic achievement.
\end{abstract}

Keywords: Self Regulated Learning, Self Efficacy, Academic Achievement

Abstrak: Penelitian ini bertujuan untuk mengetahui: pengaruh self regulated learning terhadap prestasi akademik mahasiswa, (2) pengaruh Self Efficacy terhadap prestasi Akademik; (3) pengaruh Self Regulated Learning dan Self Efficacy terhadap prestasi Akademik. Populasi dalam penelitian ini adalah Mahasiswa Semester II sebanyak 70 mahasiswa, sampel penelitian sebanyak jumlah populasi yakni 70 mahasiswa. Metode yang digunakan adalah analisis regresi linear berganda. Hasil penelitian menunjukkan bahwa: (1) Self regulated learning tidak berpengaruh terhadap prestasi akademik mahasiswa, (2). Self efficacy secara signifikan berpengaruh terhadap prestasi akademik mahasiswa, dan (3). Self regulated learning dan Self efficacy secara simultan berpengaruh terhadap prestasi akademik mahasiswa.

Kata Kunci: Self Regulated Learning, Self Efficacy, Prestasi Akademik

\section{PENDAHULUAN}

Di era teknologi dan informasi ini, paradigma pembelajaran berpusat pada peserta didik atau Student Centered Learning dipandang lebih baik dibanding pembelajaran berpusat pada pendidik atau Teacher Centered Learning. Pembelajaran Student Centered Learning memberikan kebebasan peserta didik, di mana mereka lebih aktif dibanding pendidik, diasumsikan bahwa peserta didik memegang peran yang sangat penting dalam aktivitas belajar mereka, seperti menentukan apa yang akan dipelajari, kapan mereka belajar dan bagaimana cara mereka belajar, pebelajar memiliki control penuh terhadap akivitas belajarnya. Peserta didik merupakan kunci dalam pembelajaran, mereka bertanggung jawab untuk pembelajaran mereka mulai dari awal sehingga membuat mereka lebih mandiri. Student Centered Learning membentuk peserta didik sesuai dengan kodratnya sendiri, tidak tergantung pada keinginan pendidik, sehingga ,uncul kreativitas dan kebebasan dalm belajar (Yucel Gelisli, 2009). Dengan meningkatnya kontrol diri yang dimiliki oleh peserta didik, maka kemampuan untuk 
mengatur pembelajaran, pengambilan keputusan pribadi dan perilaku positif seperti disiplin akan meningkatkan prestasi akademik, (Hannon, Brenda Ann Marie 2014 ), dan hal ini akan sangat penting bagi mereka dalam meraih kesuksesan mereka dalam belajar dan menjadikan mereka pebelajar seumur hidup ( Regeluth 2017), dan kemampuan ini merupakan catatan yang sangat penting terkait dengan skill atau kompetensi yang harus dimiliki oleh pebelajar abad 21 ( Wolters,2010).

Prestasi akademis atau kinerja akademis adalah sejauh mana capaian tujuan pendidikan oleh peserta didik, pendidik atau institusi baik jangka pendek atau jangka panjang.. Prestasi akademik diukur dengan indeks prestasi kumulatif (IPK ), nilai raport, penyelesaian studi pada suatu jenjang pendidikan sekolah dasar sampai perguruan tinggi. Prestasi akademik sangat erat kaitannya dengan kemampuan pebelajar dalam mengatur dirinya untuk belajar serta keyakinan atas kemampuan yang dimiliki oleh peserta didik untuk mencapai tujuan. Hasil penelitian menunjukan bahwa selfefficacy dan self regulated learning memilki interaksi positif satu sama lain. Keyakinan atas kemampuan (selfefficacy) yang lebih tinggi meningkatkan penggunaan self regulated learning (Pajares, 2008) dan penggunaan self regulated learning dapat meningkatkan self-efficacy dan prestasi akademik (Zimmerman \& Martinez-Pons, 1990).

Self Regulated Learning berperan penting dalam membantu peserta didik mengelola pemikiran, perilaku dan emosi mereka agar berhasil mengatur pengalaman belajar mereka. Dalam kegiatan pembelajaran SRL sangat penting (Jarvela \& Jarvenoja, 2011;
Zimmerman, 2008). Dengan SRL dapat membantu siswa menciptakan kebiasaan belajar yang lebih baik dan memperkuat kemampuan belajar mereka (Wolters, 2011), dapat meningkatkan hasil akademik (Harris, Friedlander, Sadler, Frizzelle, \& Graham, 2005), dapat memonitor kinerja mereka (Harris et al., 2005), dan mengevaluasi kemajuan akademis mereka (De Bruin, Thiede \& Camp, 2011). Nilyun Aksan (2009) menyatakan bahwa peserta didik yang memiliki self Regulated learning yang baik memiliki kemampuan untuk mengatur proses belajarnya, menilai hasil belajarnya.

Self efficacy juga mempengaruhi peserta didik dalam, usahanya, ketekunannya, untuk menyelesaikan tugas dan juga prestasinya (Santrock 2008:298). Pebelajar yang memiliki self efficacy tinggi akan memiliki prestasi akademik tinggi sebaliknya pebelajar dengan self efficacy rendah memiliki kinerja yang rendah (Angela Willson-Conrad and Megan Grunert Kowalske 2017). Keyakinan siswa akan kemampuan mereka untuk berhasil menyelesaikan tugas-juga berperan, terutama selama tahap peramalan pemikiran dan perencanaan dan pemantauan kinerja (Zimmerman, 2000).

\section{METODE PENELITIAN}

Metode penelitian yang digunakan adalah metode penelitian kuantitatif, dengan pendekatan deskriptif, di mana penelitian ini bertujuan untuk mengetahui apakah ada pengaruh antara masingmasing variabel. Variabel dalam penelitian ini terdiri atas variabel bebas adalah $S R L$ ( $\mathrm{X} 1), \mathrm{S} E(\mathrm{X} 2)$, dan variabel terikat $(\mathrm{Y})$ adalah prestasi akademik mahasiswa. Populasinya adalah mahasiswa Jurusan PAK semester dua sebanyak 70 orang mahasiswa, sedangkan sampel yang digunakan adalah keseluruhan dari 
populasi. Instrumen penelitian menggunakan angket untuk mengukur self regulated learning dan self efficacy dengan menggunakan skala likert dengan opsi jawaban sangat setuju sekali, sangat setuju, setuju tidak setuju, tidak setuju sekali. Data penelitian terdiri dari dua yaitu data primer dan data sekunder. Data primer adalah data angket self regulated learning dan self efficacy, sedangkan data sekunder adalah prestasi akademik mahasiswa yakni indeks prestasi mahasiswa PAK semester dua. Teknik analisa data yang digunakan adalah analisis regresi liniear berganda dengan menggunakan SPSS versi 24.

\section{HASIL DAN PEMBAHASAN}

Setelah melakukan penelitian terhadap responden sebanyak 70 orang mahasiswa hasil yang diperoleh terkait dengan SRL, $S E$ dan prestasi akademik dideskripsikan sebagai berikut:

\section{Uji Asumsi Klasik}

Sebelum melakukan uji regresi berganda maka perlu melakukan uji Asumsi klasik sebagai prasyarat. Uji Asumsi klasik meliputi Normalitas, multikolinieritas, hetroskedasitas dan uji lineritas. Setelah dilakukan uji asumsi klasik berdasarkan data penelitian yang diperoleh maka hasil menunjukan bahwa tidak ada masalah, artianya semua uji asumsi klasik memenuhi syarat untuk melakukan analisis regresi berganda. Hasil uji asumsi klasik terlihat di tabel berikut ini:

Tabel 1. Hasil Uji Asumsi Klasik

\begin{tabular}{llll}
\hline \multicolumn{1}{c}{$\begin{array}{c}\text { Uji Asumsi } \\
\text { Klasik }\end{array}$} & $\begin{array}{c}\text { Uji yang } \\
\text { digunakan }\end{array}$ & \multicolumn{1}{c}{ Hasil } & \multicolumn{1}{c}{ Kesimpulan } \\
\hline Normalitas & Kolmogorov & Sig Self Regulated learning $=$ & Data berdistribusi \\
& Smirnov & 0,165 & normal \\
& Test & Sig Self Efficacy $=0.105$ & \\
& & Sig Prestasi Akademik $=0.75$ & Tidak ada \\
Multikolinieritas & Variance & VIF Self Regulated Learning & Multikolinieritas \\
& Inflation & $=0,690$ & Tidak ada \\
Heteroskedasitas & Factor (VIF) & VIF Self Efficacy $=0,627$ & Heteroskedasitas \\
& Uji Glejser & Sig Self Regulated Learning $=$ & Terdapat hubungan \\
Linieritas & & Sig Self Efficacy $=$ & Linieritas varibael X \\
& Test & Sig Self Regulated $=$ & dengan variabel Y \\
\hline
\end{tabular}

Coefficients $^{\mathrm{a}}$

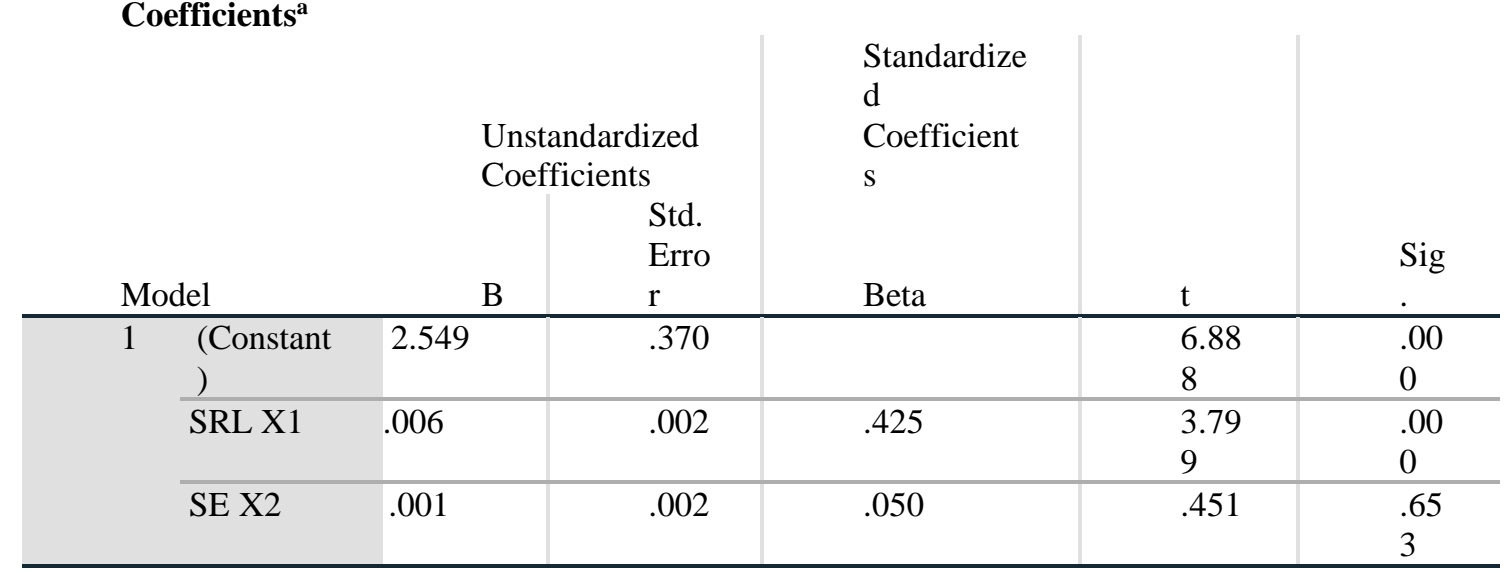

Tabel 2. Hasil Uji Regresi Berganda 
a. Dependent Variable: PRESTASI AKADEMIK

Adjusted R Square : 0.153

Rsquare : 0,177

Berdasarkan hasil analissi regresi linier berganda maka diperoleh nilai konstan sebesar 2,549, sedangkan nilai untuk variabel self regulated learning ( $\mathrm{X} 1$ ) sebesar 0.006, self efficacy (X2) sebesar 0.001. sehingga apabila dimaskukan dalam persamaan regresi dalam analisis penelitian ini adalah sebagai berikut: $\mathrm{Y}=\mathrm{a}+\mathrm{b} 1 \mathrm{x} 1+\mathrm{b} 2 \times 2$ atau $\mathrm{Y}=$ $2.549+0.06 \mathrm{X} 1+0.001 \mathrm{X} 2+$

Persamaan regresi tersebut mengandung arti apabila ada kenaikan self regulated learning sebesar satu satuan maka prestasi akademik mahasiswa akan meningkat sebesar 0.006 dengan asumsi bahwa variabel lain bernilai tetap dan kenaikan self efficacy sebesar satu satuan akan berdampak pada meningkatnya prestasi akademik mahasiswa akan meningkat sebesar 0.001 dengan asumsi bahwa variabel lain bernilai tetap.
Sementara untuk konstanta sebesar 2.549 mengandung arti apabila self regulated learning (X1) dan self efficacy (X2) nilai adalah 0, maka prestasi akademik (Y) nilainya adalah 2.549. Selain itu nilai koefisien determinasi ( Adjusted R Square) sebesar 0.153. hal ini menunjukan bahwa perubahan variabel prestasi akademik sebesar $15.3 \%$ dipengaruhi oleh self regulated learning dan self efficacy. Sedangkan $84.7 \%$ merupakan faktor lain seperti minat, motivasi, bakat, gaya belajar, kesehatan, keluarga, dll. Hasil penelitian ini senada dengan hasil penelitian Dinar Tiara, dkk. Bahwa faktorfaktor yang mempengaruhi hasil belajar antara lain motivasi, minat, kesehatan, keluarga, bakat cara belajar, dan lingkungan sekitar.

Tabel 3 Pengaruh Variabel Bebas terhadap Terikat secara Parsial

\begin{tabular}{lll}
\hline Varibael Bebas & Sig & Keterangan \\
\hline Self Regulated Learning & 0.000 & Ho Diterima \\
Self Efficacy & 0.627 & Ho Diterima \\
\hline
\end{tabular}

Tabel di atas menunjukan bahwa self regulated learning mempunyai nilai sig sebesar 0.000, ( $\mathrm{sig}<0.005)$. artinya tidak ada pengaruh self regulated learning terhadap prestasi akademik mahasiswa pada mata kuliah Teori Belajar. Sedangkan untuk variabel self efficacy diperoleh nilai sebesar 0.627 ( $\mathrm{sig}>0.005$.) artinya bahwa ada pengaruh positif /tidak varibael self efficacy terhadap prestasi akademik mahasiswa pada mata kuliah Teori Belajar.

Tabel 4. Hasil Sumbangan Efektif

\begin{tabular}{|c|c|c|c|}
\hline \multirow[t]{2}{*}{ Variabel Bebas } & $\begin{array}{l}\text { Standarized } \\
\text { Coefficient }\end{array}$ & Korelation & Jumlah Perhitungan \\
\hline & Beta $\beta$ & & B X rxy X 100\% \\
\hline $\begin{array}{l}\text { Self regulated Learning } \\
\text { (X1) }\end{array}$ & $(-0.049)$ & $(-0.048)$ & $23,35 \%$ \\
\hline $\begin{array}{l}\text { Self Efficacy (X2) } \\
\text { Total }\end{array}$ & $(-0.060)$ & $(-0.059)$ & $35,4 \%$ \\
\hline
\end{tabular}

Tabel di atas menunjukan bahwa variabel bebas yang berpengaruh secara dominan terhadap prestasi akademik mahasiswa pada mata kuliah Teori Belajar 
adalah varibael self efficacy yakni sebesar $35,4 \%$

Tabel 5. Hasil Uji Hipotesis Data Penelitian

\begin{tabular}{llll}
\hline Hipotesis & Hasil & Sumbangan Efektif & Kesimpulan \\
\hline Hipotesis 1 & Sig $=0.000$ & $23.52 \%$ & $\begin{array}{l}\text { Tidak pengaruh self regulated learning } \\
\text { terhadap prestasi akademik }\end{array}$ \\
Hipotesis 2 & Sig $=0.653$ & $35,4 \%$ & $\begin{array}{l}\text { Ada pengaruh self efficacy terhadap } \\
\text { prestasi akademik }\end{array}$ \\
Hipotesis 3 & Sig $=0.001$ & $17.7 \%$ & $\begin{array}{l}\text { Ada pengaruh self regulated learning } \\
\text { dan self efficacy terhaadap prestasi } \\
\text { akademik }\end{array}$ \\
\hline
\end{tabular}

\section{Ada Pengaruh Self Regulated Learning Terhadap Prestasi Akademik Mahasiswa}

Penelitian terkait dengan self regulated learning telah banyak dilakukan, hasil penelitian yang didapatpun sangat beragam, demikian juga untuk penelitian tentang self regulated learning dan prestasi akademik. Hasil penelitian yang diperoleh tentang kedua variabel ini sangat beragam. Beberapa hasil penelitian menunjukan bahwa adanya pengaruh yang posistif antara self regulated learning dan prestasi akademik, tetapi ada pula yang menemukan adanya pengaruh yang negatif antara self regulated learning dengan prestasi akademik. Menurut hasil penelitian yang dilakukan oleh Mei dan Liayana ( dalam Sitepu,2014) terhadap mahasiswa fakultas Sains Universitas Sains Malaysia, labih lanjut dikemukan bahwa Self regulated Learning merupakan salah satu faktor yang tururt mempengaruhi prestasi akademik mahasiswa, hasil penelitian ini sesuai dengan apa yang dikemukan oleh Bell dan Akroyd, (2006) bahwa prestasi seseorang dipengaruhi oleh Self Regulated learning yang merupakan bagian teori pembelajaran kognitif.

Dalam penelitian ini juga menemukan adanya hasil yang kontradiktif di mana tidak ada pengaruh yang signifikan self regulated learning terhadap prestasi akademik mahasiswa semester dua. Hasil ini juga didukung oleh Anggaini (2010). Menurutnya tidak terdapat hubungan antara self regulated learning dan prestasi akademik, demikian juga penelitian yang dilakukan oleh Kurniawati \& Leonardi, (2013). Hasilnya menunjukan bahwa tidak ada hubungan antara metacognition regulation dengan prestasi akademik pada mahasiswa yang aktif berorganisasi di kampus. Hasil ini juga sesuai dengan penelitian Supriyanto (2015), yang dilakukan pada mahasiswa semesetr pertama (tahun 2014/2015) bahwa tidak ada hubungan yang signifikan antara self regulated learning dan prestasi akademik.

Tidak signifikansi korelasi antara self regulated learning dan prestasi akademik menurut Ajiksukmo, (1996), dapat saja terjadi karena adanya perbedaaan individu antara siswa yang satu dengan siswa yang lain.. misalnya terdapat perbedaan individu dalam menggunakan strategi-strategi yang berbeda dalam situasi yang sama. Selain itu self regulated learningnya turut dipengaruhi oleh sudut pandang peserta didik terhadap apa yang dipelajari. Ketika mereka memandang belajar sebagai sesuatu hal yang penting maka mereka akan meregulasi diri mereka dengan baik. 


\section{Ada Pengaruh self Efficacy terhadap Prestasi Akademik Mahasiswa}

Hasil uji regresi menunjukan bahwa terdapat pengaruh yang signifikan self efficacy terhadap prestasi akademik mahasiswa. Hasil penelitian ini mendukung penelitian sebelumnya yang dilakukan oleh (Rahman et al., 2017) yang mengemukakan bahwa self efficacy berpengaruh positif dan signifikan terhadap hasil belajar. Hasil penelitian ini sejalan dengan (Azar, et al., 2017) yang menyatakan bahwa self efficacy memberikan pengaruh secara langsung dan secara positif terhadap nilai tugas, tujuan penguasaan, kinerja, tujuan pendekatan, pendekatan mendalam, dan prestasi akademik.

Hasil penelitian ini juga sejalan dengan (Tuhardjo, Juliardi, \& Rafsanjani, 2016) yang menemukan bahwa terdapat pengaruh positif yang signifikan antara self efficacy untuk hasil belajar Akuntansi. Dengan demikian, keberhasilan pebelajar dalam mendapatkan hasil belajar yang baik dapat dilihat dari tingkat self efficacy yang ia miliki. Semakin tinggi tingkat self efficacy pebelajar dalam belajar maka akan mampu mendorong pebelajar untuk mendapatkan hasil belajar yang optimal.

Hasil penelitian ini juga didukung oleh hasil penelitian ( Fatiyah.,dkk, 2016) yang mengemukakan bahwa Self Efficacy secara signifikan berpengaruh terhadap hasil belajar siswa dengan sumbangan efektif sebesar $15.80 \%$. menurutnya mereka yang memiliki self efficacy rendah maka akan memperoleh nilai yang rendah juga. Self efficacy atau keyainan diri memberikan pengaruh positif terhadap prestasi akademik seseorang. Hal ini dikarenakan keyakinan diri yang dimiliki seseorang menimbulkan rasa percaya diri/optimis akan kemampuan yang dimiliki dalam mengerjakan tugas atau menyelesaikan tugas yang diberikan sekalipun mereka menemui kendala, mereka tetap optimis dengan kemampuan yang mereka miliki, sehingga membuat mereka mampu untuk menyelesaikan setiap tugas yang diberikan. Sebaliknya apabila seseorang memiliki keyakinan diri yang rendah atau pesimis dengan kemampuan yang dimilikinya, maka akan berpengaruh terhadap kemampuannya untuk menyelesaikan tugas yang diberikan. Hal ini dipertegas oleh (Javanmard, dkk., 2012) bahwa "individuals with low selfefficacy are pessimist about their abilities; hence they avoid situations deemed beyond their abilities".

\section{Ada Pengaruh Self Regulated Learning Dan Self Efficacy Secara Simultan Terhadap Prestasi Akademik Mahasiswa}

Hasil penelitian menunjukan bahwa kedua variabel, yakni variabel X1( self regulated learning) dan variabel $\mathrm{X} 2$ (self efficacy) secara simultan mempengaruhi prestasi akademik mahasiswa. Adanya hubungan antara variabel self regulated learning dan self efficacy tehadap prestasi belajar mahasiswa, sesuai dengan penelitian yang dilakukan oleh Altun dan Erden, (2013). Melalui penelitian yang dilakukan dengan judul Strategi Pembelajaran berbasis Self Regulation learning dan persepsi Self efficacy sebagai prediktor prestasi akademik siswa laki-laki dan perempuan, hasilnya menunjukan bahwa kedua variabel ini secara simultan mempengaruhi prestasi akademik matematika. Lebih lanjut dikatakan bahwa self efficacy dan self regulation meliputi metakognitif, regulasi waktu dan lingkungan belajar, help seeking, faktor faktor inilah yang sangat signifikan dalam mempengaruhi prestasi akademik.

Hasil penelitian yang lain yang dilakukan oleh Bekti Dwi, (2014) yang bertujuan untuk mengetahui hubungan 
antara self regulated learning dan self efficacy dengan prestasi akademik pada siswa SMA N 2 Bangkalan, hasil penelitian menunjukan bahwa terdapat hubungan antara self regulated learning dan self efficacy terhadap prestasi akademik akademik siswa SMAN 2 Bangkalan.

Purwanto, (2014) mengemukan bahwa faktor-faktor internal yang turut mempengaruhi penyelenggaraan pendidikan adalah self regulated learning dan self efficacy. Jika seseorang memiliki self efficacy ( memiliki keyakinan diri pada kemampuan yang dimilikinya ) maka ia akan optimis untuk mengerjakan setiap tugas yang diberikan kepadanya, sebaliknya jika sesorang tidak memiliki self efficacy diri atau kurang memiliki, maka Ia akan pesimis untuk mengerjakan tugas yang diberikan guru baginya.

Altun dan Erden, mengemukakan bahwa self regulated learning secara spesifik dipandang sebagai proses proaktif yang digunakan siswa untuk memperoleh keterampilan akademis, seperti menetapkan tujuan, memilik strategi belajar, memonitor dan mengevaluasi hasil serta menetapkan tujuan belajar yang baru setelah hasil evaluasi. Mereka cenderung memiliki hasil belajar yang baik. Sehingga dengan kemampuan pembelajar untuk mengatur belajarnya secara mandiri dengan meyakini akan kemampuan yang dimilikinya, maka pembelajar akan mendapatkan prestasi akademik yang baik.

\section{SIMPULAN}

Berdasarkan hasil penelitian di atas maka dapat disimpulkan bahwa: 1) Self regulated learning tidak berpengaruh terhadap prestasi akademik mahasiswa, 2) Self efficacy secara signifikan berpengaruh terhadap prestasi akademik mahasiswa, 3) Self regulated learning dan Self efficacy secara simultan berpengaruh terhadap prestasi akademik mahasiswa.

Berdasarkan hasil penelitian ini diharapkan agar mahasiswa dalam upaya untuk meningkatkan prestasi akademiknya agar dapat meregulasi diri secara mandiri dalam proses pembelajaran serta memiliki keyakinan terhadap kemampuan akademik yang dimiliki, karena kedua faktor ini turut mempengaruhi prestasi akademik mahasiswa.

\section{DAFTAR RUJUKAN}

Altun, Sertel \& Erden, Munire. (2013). Self-Regulation based Learning Strategies and Self-Efficacy Perceptions as Predisctors of Male and Female Student's Mathematic Achievement. Procedia-Social and Behavioral Science, 106(1): 23542364,

(Online),

www.sciencedirect.com,

Azar, H., K., Malahmadi, L., E., Amani,J. (2010).The role of self- efficacy,task value, and achievement goalsin predicting learning approachesand mathematics achievement.ProcediaSocial and BehavioralSciences, 5,

Angela Wilson - Conrad and Megan Grunert Kowalske, (2017), self-efficacy beliefs to understand how students in a general chemistry course approach the exam process.(chemistry education research and practice).

Bekti Dwi, (2014) Hubungan Antara SelfEfficacy Dan Self-Regulated Learning Dengan Prestasi Akademik Matematika Siswa Sman 2 Bangkalan, Jurnal Character.volume 03 No 2

Bell, P.D. dan Akroyd, D. 2006. Can Factors Related toSelf Regulated Learning Predict LearningAchievement in Undergraduate

AsynchronousWebbased Courses? International Journal of Instructional 
Educatio and Distance..ISSN : 15506908

Dinar Tiara Nadip Putri, Gatot Isnani, (2015). Pengaruh Minat Dan Motivasi Terhadap Hasil Belajar Pada Mata Pelajaran Pengantar Administrasi Perkantoran, jurnal pendidikan Bisnis dan Manajemen.

Fatiyah.,et.al,(2016) Pengaruh Kebiasaan Belajar Dan Self-Efficacyterhadap Hasil Belajar Geografi Di SMA. Jurnal Pendidikan Geografi Univesitas Negeri Malang.

Jarvela, Javarnevo, (2014)., Socially Constructed Self-RegulatedLearning and Motivation Regulation inCollaborative Learning Groups

Javanmard,Ali et.al (2012). Investigating the relationship between self efficacy, cognitive anmetacognitive strategies, and academic self handicapping with academicachievement in male high school student in the Tribes of Fars Province. JournalLife science Biomed.

Kurniawati, R. \& Leonardi, T. 2013. Hubungan antara metakognisi dengan prestasi akademik pada mahasiswafakultas psikologi universitas airlangga yang aktif berorganisasi di organisasi mahasiswa tingkat fakultas. Jurnal Psikologi Pendidikan dan Perkembangan: 01 Vol. 2, No. 01, April 2013.

Pintrich, P.R. 2000. The Role of goal orientation in self-regulated learning. In M. Bokaerts, P. Pintrich, \& M. Zeidner (Eds) Handbook of selfregulation. San Diego, CA: Academic Press,

\footnotetext{
Purwanto,Ngalim.(2014) Psikologi Pendidikan. Bandung: Remaja Rosdakarya
}

Rahman, U., Sulasteri, S., Yasin, J. H.,Kunci, K. (2017).Pengaruh EfikasiDiri, Harga Diri Dan MotivasiTerhadap Hasil Belajar MatematikaPeserta Didik Kelas X Sma Negeri1 Bulupoddo Kab. Sinjai. Jurnal Matematika Dan Pembelajaran, 5(1),

Santrock.J.W, (2008) Psikologi Pendidikan, Kencana Prenada Media Group, Jakarta

Schunk, DH \& Zimmerman.BJ. 1998. Self Regulated and Performance: Issues and Educational Application. Hillsdale, NJ: Lawrence L-Erlbaum Association, Inc.

Supriyanto,S.Psi.,M.Si,(2015). Hubungan Antara Self-Regulated Learning Dan Prestasi Akademik Pada Mahasiswa Semester Pertama Prodi Psikologiuniversitas Pembangunan Jaya, Jurnal Universitas Pembangunan Jaya \#2 Volume 2 Maret.

Tuhardjo.,et.al, (2016)The Effect of Learning Effectiveness and SelfEfficacy on Intermediate Financial Accounting I Learning outcomeSeptember 2016IOSR Journal of Humanities and Social Science

Wolters, Christopher. A., Pintrich, Paul. R., dan Karabenick, Stuart. A. 2011. Assessing Academic Self Regulated Learning. Conference on Indicator ofPositive Development: Child Trends, National Institute of Health

Yucel Gelisli, (2009) The Effect of Student Centered Instructional Approaches on Student Success. Procedia Social and Behavioral Sciences 1 (2009) 469473

Zimmerman, B.J.1989. A Social Cognitive View of Self Regulated Academic Learning. Journal Edducational Psychology.81,(4):329-339. 
Zimmerman, B.J.1989. Self Regulated Learning and Academic Achievement. Journal Edducational Psychology

Zimmerman, B.J. \& Bandura, A. 1994. Dimension of Academic Self regulation A Conceptual Framework for Education. In D.H.Schunk 
80 JURNAL PENDIDIKAN EDUTAMA, Vol.8, No.1 Januari 2021 